OPEN ACCESS

Edited by:

Jiuquan Zhang,

Chongqing University, China

Reviewed by:

Emilia lannilli,

University at Albany, United States

Mojgan Hodaie,

University of Toronto, Canada

*Correspondence:

Min Cheol Chang

wheel633@gmail.com

Specialty section:

This article was submitted to

Perception Science,

a section of the journal

Frontiers in Neuroscience

Received: 03 August 2020

Accepted: 25 February 2021

Published: 26 March 2021

Citation:

Yang S, Kwon S and Chang MC (2021) The Usefulness of Diffusion Tensor Tractography in Diagnosing Neuropathic Pain: A Narrative Review.

Front. Neurosci. 15:591018.

doi: 10.3389/fnins.2021.591018

\section{The Usefulness of Diffusion Tensor Tractography in Diagnosing Neuropathic Pain: A Narrative Review}

\author{
Seoyon Yang ${ }^{1}$, SuYeon Kwon ${ }^{1}$ and Min Cheol Chang ${ }^{2 *}$ \\ 'Department of Rehabilitation Medicine, Ewha Women's University Seoul Hospital, Ewha Women's University School \\ of Medicine, Seoul, South Korea, ${ }^{2}$ Department of Rehabilitation Medicine, College of Medicine, Yeungnam University, \\ Daegu, South Korea
}

Diffusion tensor tractography (DTT) is derived from diffusion tensor imaging. It has allowed visualization and estimation of neural tract injury, which may be associated with the pathogenesis of neuropathic pain (NP). The aim of the present study was to review DTT studies that demonstrated the relationship between neural injuries and NP and to describe the potential use of DTT in the evaluation of neural injuries that are involved in the pathophysiological process of NP. A PubMed search was conducted for articles published until July 3, 2020, which used DTT to investigate the association between neural injuries and NP. The key search phrase for identifying potentially relevant articles was (diffusion tensor tractography AND pain). The following inclusion criteria were applied for article selection: (1) studies involving patients with NP and (2) studies in which DTT was applied for the evaluation of NP. Review articles were excluded. Altogether, 108 potentially relevant articles were identified. After reading the titles and abstracts and assessment of eligibility based on the full-text articles, 46 publications were finally included in our review. The results of the included studies suggested that DTT may be beneficial in identifying the pathophysiological mechanism of NP of various origins including central pain caused by brain injuries, trigeminal neuralgia, sciatica, and some types of headache. Further studies are needed to validate the efficacy of DTT in investigating the pathophysiology of other types of NP.

Keywords: diffusion tensor imaging, diffusion tensor tractography, central post-stroke pain, trigeminal neuralgia, sciatica, headache

\section{INTRODUCTION}

Neuropathic pain is a localized sensation of unpleasant discomfort that results from a lesion or a disease of the peripheral or the central somatosensory system (Zhang et al., 2020). Common symptoms of NP include abnormal sensations (dysesthesia) and pain from non-painful stimuli (allodynia). Patients often complain of spontaneous ongoing or shooting pain, with evoked

Abbreviations: $\mathrm{CH}$, cluster headache; $\mathrm{CN} \mathrm{V}$, fifth cranial nerve; $\mathrm{CNS}$, central nervous system; CPP, chronic pelvic pain; CPSP, central post-stroke pain; CRPS, complex regional pain syndrome; CST, corticospinal tract; DTI, diffusion tensor imaging; DTT, diffusion tensor tractography; FA, fractional anisotropy; GKRS, Gamma knife radiosurgery; ICH, intracerebral hemorrhage; MD, mean diffusivity; MRI, brain magnetic resonance imaging; MS-TN, trigeminal neuralgia secondary to multiple sclerosis; NP, neuropathic pain; RD, radial diffusivity; ROI, region of interest; rTMS, repetitive transcranial magnetic stimulation; STT, spinothalamic tract; SUNCT, short-lasting unilateral neuralgiform headaches with conjunctival injection and tearing; TBI, traumatic brain injury; TN, trigeminal neuralgia; TV, tract volume. 
amplified pain responses after noxious or non-noxious stimuli (Baron et al., 2010). There are many different types of NP. Some of the common syndromes of NP are stroke-related central pain, TN, sciatica, and some types of headache. Medication is often applied initially for the treatment of NP, but NP tends to be refractory to conventional analgesics such as non-steroidal anti-inflammatory drugs, antidepressants, and opioids. Interdisciplinary approach, including neuromodulation treatments such as rTMS, transcranial direct current stimulation, and deep brain stimulation, is often needed for the treatment of NP. Identifying the pathophysiological mechanism of NP is important, as it can lead to a more effective and specific mechanism-based treatment approach.

Brain magnetic resonance imaging identifies a specific lesion as spotty appearance, but it cannot visualize neural tract injury. Some patients suffer from NP without showing any abnormal findings on conventional MRI or computed tomography, but their symptoms may be induced by microscopic injury of the neural tracts (Boudier-Revéret et al., 2020). DTT is a recently developed three-dimensional reconstruction technique of DTI. It shows fiber bundles with connectedness of voxels having similar diffusion properties (Oh et al., 2018). It is commonly applied in neurosurgical settings to avoid damage to surrounding vital neural pathways and to guide deep brain stimulation electrodes toward their targets (Zhang et al., 2020). DTT allows a quantitative analysis of healthy and pathological nerves, myelin sheaths, and muscles and enables the assessment of neural tract injuries at a microscopic level (Chianca et al., 2017).

Neuropathic pain can develop following nerve injury after neurons are injured. It occurs when harmful changes have occurred along the nociceptive and the descending modulatory pathways in the CNS (Cohen and Mao, 2014). Clarification of the pathophysiological mechanism of NP may provide clues for effective treatment modalities to treat patients suffering from NP. Several studies have been conducted to investigate the injuries of neural tracts in patients with NP. The aim of the present study was to review DTT studies that demonstrated the relationship between neural injuries and NP, and to describe the potential use of DTT in the evaluation of neural tract injuries that are involved in the pathophysiological process of NP.

\section{METHODS}

Studies that investigated neural injuries in various types of NP using DTT were searched. We searched the MEDLINE database (PubMed) for relevant studies published until July 3, 2020. The key search phrase for identifying potentially relevant articles was (diffusion tensor tractography AND pain). The following inclusion criteria were applied for the selection of articles: (1) studies involving patients with NP and (2) studies in which DTT was applied for the evaluation of NP. This review was limited to studies involving humans with NP. The relevant studies were selected according to the flow diagram shown in Figure 1. Altogether, 108 potentially relevant articles were identified. After reading the titles and abstracts and assessing the eligibility based on the full-text articles, 46 publications were included in our review. Studies eligible for the review included 20 studies on central pain caused by brain injuries, 11 studies on TN, 7 studies on sciatica, 5 studies on headache, 1 study on thoracic outlet syndrome, and 2 studies on CPP (Table 1 and Figure 2).

A combined ROI method, which reconstructs the neural fibers passing more than two ROI areas, is usually used in DTT studies for reconstruction of the neural tracts (Jang et al., 2019b). The entire neural tract can be evaluated in terms of DTT parameters. Commonly used DTT parameters are FA, MD, and TV. FA reflects the degree of directionality of water diffusion. It is used to estimate the degree of directionality and the integrity of white matter microstructures including axons, myelin, and microtubules. MD reflects the degree of water diffusion. In conditions such as vasogenic edema or axonal damage, it exhibits a tendency to increase. TV indicates the number of voxels included in the neural tract. Neural injury is assumed to be present when there are decreases in the values of FA and TV and increases in the value of MD (Assaf and Pasternak, 2008; Jang et al., 2019b). Some limitations of DTT should also be considered. DTT may underestimate the fiber tracts. It may show the gross fiber architecture, but cannot demonstrate the functional or synaptic connections. The results of DTT may differ according to the operator, as the fiber tracking technique is operator dependent. Complete reflection of the fiber architecture may be hampered in regions where the fibers are complex and where they cross each other.

\section{DIFFUSION TENSOR TRACTOGRAPHY FOR DIAGNOSIS OF VARIOUS TYPES OF NEUROPATHIC PAIN}

\section{Central Pain Caused by Brain Injuries}

Central pain is one of the most common types of NP. Patients with central pain suffer from various symptoms such as tingling, numbness, burning, chilling, hyperpathia, itching, and abnormal sensations. It is caused by a lesion or dysfunction of the somatosensory pathways in the CNS, which most commonly involves the brain and spinal injuries (Yang and Chang, 2020). Importantly, central poststroke pain $(\mathrm{P})$ is one of the most common sequelae of stroke, which is caused by cerebrovascular injury to the somatosensory pathway in the brain (Akyuz and Kuru, 2016). The suggested pathophysiological mechanisms of CPSP include central sensitization, changes in neural excitability due to disinhibition, alteration of the somatosensory function, changes in the thalamic function, and inflammation of the involved neural tract. Neural structures associated with CPSP include the STT, medial lemniscus pathway, thalamus, and cerebral cortex (Klit et al., 2009; Jang et al., 2019b).

Twenty studies were identified, which used DTT to investigate the presence of neural tract damage in patients with central pain that occurred after brain injuries. In a case report by Seghier et al. (2005), DTT was used to visualize the reduction in fiber density of the lateral thalamocortical tract. Goto et al. (2008) 


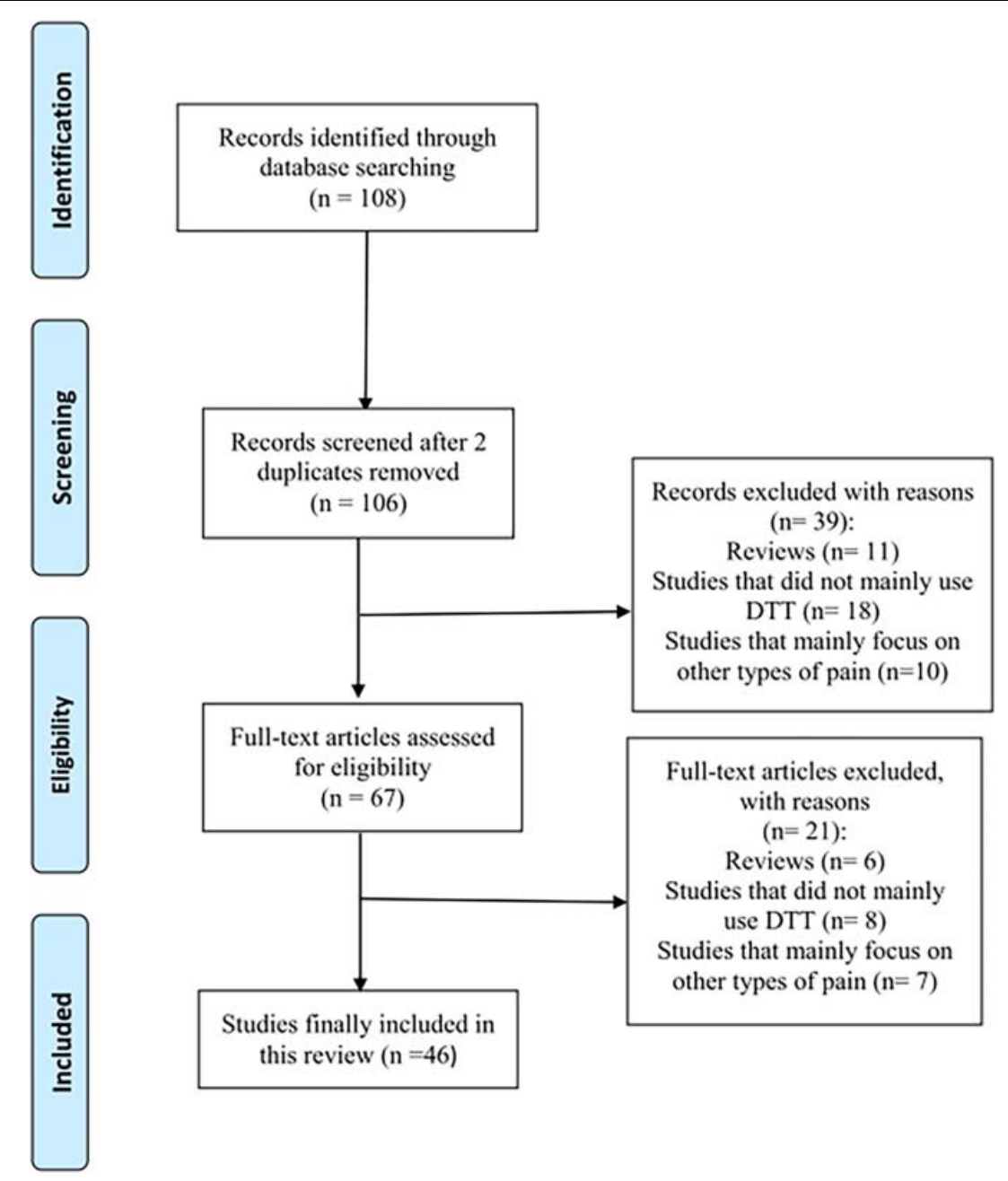

FIGURE 1 | Flow diagram of the study selection process. DTT, diffusion tensor tractography.

reconstructed the CST and the thalamocortical tract in chronic stroke patients suffering from CPSP. Some patients with CPSP showed interruption of the STT pathway. Moreover, lesions of the thalamocortical tract correlated with the efficacy of rTMS (90\% intensity of the resting motor threshold, 10 trains of 10 s, 5-Hz TMS pulses with 50-s intervals). Hong et al. (2010) used DTT to demonstrate STT injuries in patients with CPSP after ICH. Patients were divided into the CPSP group (16 patients) and the non-CPSP group (14 patients). Two ROIs were used to reconstruct the STT. MLP and fiber tracking were performed using a probabilistic tractography method. The results showed that TV was decreased without changes in the FA or MD values in the CPSP group. This study suggested that the presence of partial STT injury was associated with the development of CPSP. Hong et al. (2010) reported that the prevalence of CPSP in patients with $\mathrm{ICH}$ was higher in cases of partial STT injury when compared with that in cases of complete STT injury. Recently, Jang et al. (2017a, 2018) reported that patients with ICH who suffered from CPSP exhibited partial tearing and thinning of the STT. Furthermore, several case reports (Hirayama et al., 2014; Jang et al., 2017b) showed that disconnection of the brain pathway could lead to CPSP after acute infarction. Jang et al. (2017b) reported five patients with CPSP after cerebral infarction who showed decreased FA and TV when compared with the control group. Affected STTs passed through an adjacent part of the infarct such as the corona radiata and the thalamus, suggesting that STT injury may trigger the development of CPSP. Interestingly, a previous report described a patient who had CRPS following an ischemic stroke at the left middle cerebral artery territory (Lee et al., 2018). DTT showed a decreased number of CST and STT fibers.

Regarding central pain following TBI, several studies have demonstrated the association between neural tract damage and the development of central pain. Seo and Jang (2013, 2014) reported cases with abnormal STT findings detected using DTT, which showed that the STTs were thinner, and the FA and TV values were decreased, in patients with central pain. A retrospective study was conducted by Kim et al. (2015), which enrolled 32 patients with mild TBI. Patients were divided into 
TABLE 1 | Characteristics of the included studies.

\begin{tabular}{|c|c|c|c|c|c|c|c|}
\hline S. No. & $\begin{array}{l}\text { First } \\
\text { author }\end{array}$ & Year & $\begin{array}{l}\text { Number of } \\
\text { patients }\end{array}$ & Duration to DTT & Location of lesion & Characteristics of pain & Results \\
\hline \multicolumn{8}{|c|}{ Central pain } \\
\hline 1 & Seghier & 2005 & 1 & $4-5$ years & $\begin{array}{l}\mathrm{ICH} \text { (thalamus and } \\
\text { internal capsule) }\end{array}$ & NA & $\begin{array}{l}\text { DTT revealed a reduction in the fiber density of } \\
\text { the lateral TCT, which was presumed to be the } \\
\text { STT. }\end{array}$ \\
\hline 2 & Goto & 2008 & 17 & $\begin{array}{c}5.1 \text { years } \\
\text { (1-8.8 years) }\end{array}$ & Supratentorial stroke & $\begin{array}{l}\text { Refractory pain lasting more } \\
\text { than } 6 \text { months }\end{array}$ & $\begin{array}{c}\text { The rTMS-effective group showed higher } \\
\text { delineation ratio of the CST and the TCT than } \\
\text { the rTMS-ineffective group. }\end{array}$ \\
\hline 3 & Hong & 2010 & 30 & $\begin{array}{l}20 \text { months } \\
\text { (5-48 months) }\end{array}$ & $\begin{array}{l}\mathrm{ICH} \text { (corona radiata and } \\
\text { basal ganglia) }\end{array}$ & NA & $\begin{array}{c}\text { TV was decreased without any changes in the } \\
\text { FA or MD values in the CPSP group, indicating } \\
\text { partial STT injury. }\end{array}$ \\
\hline 4 & Hong & 2012 & 52 & $\begin{array}{l}18.8 \text { months } \\
\text { (5-46 months) }\end{array}$ & $\begin{array}{l}\text { ICH (corona radiata, } \\
\text { basal ganglia, and } \\
\text { thalamus) }\end{array}$ & NA & $\begin{array}{l}\text { Number of patients with partial STT injury was } \\
\text { higher than the number of patients with } \\
\text { complete STT injury among patients with CPSP. }\end{array}$ \\
\hline 5 & Jang & 2013 & 1 & 1 month & $\begin{array}{l}\text { TBI (thalamus and } \\
\text { ventral posterolateral } \\
\text { nucleus) }\end{array}$ & $\begin{array}{l}\text { Persistent tingling sensation } \\
\text { and pain }\end{array}$ & $\begin{array}{c}\text { The FA values of the left STT at the thalamus } \\
\text { were decreased, indicating injury of the left } \\
\text { ventral posterolateral nucleus. }\end{array}$ \\
\hline 6 & Hirayama & 2014 & 1 & 2 weeks & $\begin{array}{l}\text { Stroke (right parietal } \\
\text { operculum and insula) }\end{array}$ & $\begin{array}{l}\text { Sensation of pain decreased } \\
\text { markedly in multiple regions }\end{array}$ & $\begin{array}{l}\text { The operculo-insular lesion disrupted the } \\
\text { ipsilateral thalamo-S2 projections when } \\
\text { compared with the intact side. }\end{array}$ \\
\hline 7 & Jang & 2014 & 1 & 2 years & $\begin{array}{l}\text { TBI (axonal injuries in } \\
\text { both the cingula and in } \\
\text { the optic radiation) }\end{array}$ & Pain in multiple regions & $\begin{array}{l}\text { Both the STTs of the CPSP patient were thinner } \\
\text { in gross appearance with decreased FA and TV }\end{array}$ \\
\hline 8 & Kim & 2015 & 22 & 3-28 months & Mild TBI & NA & $\begin{array}{c}\text { Decreased FA and TV and increased MD were } \\
\text { observed in the pain group when compared } \\
\text { with the control group. }\end{array}$ \\
\hline 9 & Jang & 2016 & 1 & $\begin{array}{l}1 \text { month and } \\
9 \text { months }\end{array}$ & Mild TBI & $\begin{array}{l}\text { Pain in the hand and foot with } \\
\text { constant tingling }\end{array}$ & $\begin{array}{c}\text { On 1-month DTT, partial tearing was observed } \\
\text { in both the STTs. Both partially torn STTs had } \\
\text { atrophied on 9-month DTT. }\end{array}$ \\
\hline 10 & Jang & 2017 & 2 & 4-5 days & Mild TBI & $\begin{array}{c}\text { Pain in multiple regions with } \\
\text { tingling }\end{array}$ & $\begin{array}{l}\text { Partial tearing of the STTs was observed in both } \\
\text { patients. }\end{array}$ \\
\hline 11 & Jang & 2017 & 1 & $\begin{array}{l}1 \text { month and } \\
3 \text { years }\end{array}$ & $\begin{array}{l}\text { Corpus callosum } \\
\text { hemorrhage }\end{array}$ & $\begin{array}{l}\text { Pain in the upper and lower } \\
\text { extremities with tingling }\end{array}$ & $\begin{array}{l}\text { Disruption of transcallosal fibers in the genu } \\
\text { and the isthmus of the corpus callosum was } \\
\text { observed after } 1 \text { month and thinning of the STT } \\
\text { was observed } 3 \text { years later. }\end{array}$ \\
\hline 12 & Jang & 2017 & 1 & 4 weeks & Mild TBI & $\begin{array}{l}\text { Pain in the leg, throbbing and } \\
\text { cold pain }\end{array}$ & $\begin{array}{l}\text { The CST showed partial tearing at the } \\
\text { subcortical white matter level. Narrowing and } \\
\text { partial tearing were observed in both the STTs. }\end{array}$ \\
\hline 13 & Jang & 2017 & 5 & $\begin{array}{c}11 \text { days } \\
\text { (10-13 days) }\end{array}$ & $\begin{array}{l}\text { Cerebral infarction } \\
\text { (corona radiata and } \\
\text { thalamus) }\end{array}$ & $\begin{array}{l}\text { Pain including electric } \\
\text { shock-like sensation }\end{array}$ & $\begin{array}{l}\text { FA and TV values were decreased with STT } \\
\text { injury in the affected hemisphere in all patients. }\end{array}$ \\
\hline 14 & Choi & 2018 & 12 & 2.6 months & Mild TBI & $\begin{array}{l}\text { Pain including electric } \\
\text { shock-like sensation }\end{array}$ & $\begin{array}{l}\text { FA and TV values of the STTs were decreased } \\
\text { with partial tearing of the STTs in all patients. }\end{array}$ \\
\hline 15 & Jang & 2018 & 1 & $\begin{array}{l}2 \text { weeks and } \\
14 \text { months }\end{array}$ & Thalamic hemorrhage & $\begin{array}{l}\text { Pain in the arm and leg with } \\
\text { tingling and cold sensation }\end{array}$ & $\begin{array}{c}\text { Partial tearing and thinning was observed in the } \\
\text { left STT. }\end{array}$ \\
\hline 16 & Lee & 2018 & 1 & $\begin{array}{l}2 \text { months after } \\
\text { onset }\end{array}$ & Stroke (left MCA infarct) & Painful range of motion & $\begin{array}{c}\text { Decreased number of CST and STT fibers were } \\
\text { observed in both unaffected and affected } \\
\text { hemispheres. }\end{array}$ \\
\hline 17 & Jang & 2019 & 1 & 9 years & TBI (whiplash injury) & $\begin{array}{l}\text { Burning pain in the arms and } \\
\text { legs with constant tingling }\end{array}$ & $\begin{array}{c}\text { Both the STTs showed marked narrowing and } \\
\text { partial tearing. Partial tears were observed in } \\
\text { both the CSTs. }\end{array}$ \\
\hline 18 & Jang & 2019 & 5 & $\begin{array}{l}2 \text { days to } \\
14 \text { months }\end{array}$ & Mild TBI & $\begin{array}{l}\text { Pain including electric } \\
\text { shock-like sensation }\end{array}$ & $\begin{array}{c}\text { The FA values were decreased and the STT } \\
\text { showed partial tearing in at least one } \\
\text { hemisphere. }\end{array}$ \\
\hline 19 & Jang & 2019 & 1 & 4 years & Mild TBI & $\begin{array}{l}\text { Intermittent, squeezing, and } \\
\text { warm creeping-like pain in the } \\
\text { abdomen }\end{array}$ & $\begin{array}{l}\text { The upper portion of the STTs in both } \\
\text { hemispheres showed partial tearing. }\end{array}$ \\
\hline 20 & Jang & 2019 & 1 & 2 months & Mild TBI & Pain with burning sensation & $\begin{array}{l}\text { Partial tearing of the CST was observed at the } \\
\text { subcortical white matter in both hemispheres. } \\
\text { Tearing was much more severe in the left CST. }\end{array}$ \\
\hline
\end{tabular}


TABLE 1 | Contiued

\begin{tabular}{|c|c|c|c|c|c|c|c|}
\hline S. No. & $\begin{array}{c}\text { First } \\
\text { author }\end{array}$ & Year & $\begin{array}{c}\text { Number of } \\
\text { patients }\end{array}$ & Duration to DTT & Location of lesion & Characteristics of pain & Results \\
\hline
\end{tabular}

\section{Trigeminal neuralgia}

$21 \quad$ Hodaie 2012

22

Wilcox 2015

23

Chen $\quad 2016 \quad \begin{array}{r}20(10 \mathrm{TN} \\ \text { and 10 } \\ \text { MS-TN })\end{array}$

24

25

Burkett

2017

17

Hayes $\quad 2017 \quad 37$

26

Moon

27

28

29

Rutland $2019 \quad 10$

30

Choi

2020

31

Yoshida

2020

\section{Sciatica}

32

Chuanting 2014

$33 \quad$ Oikawa $2015 \quad 34$

34

Shi

2015

75

4-12 months

35

Eguchi

2016

1

5 years

36

Wu

2016

34

37

2016

40

0.3-6 months

38

Shi

2020

36

NA

Headache

39

$2014 \quad 17 \quad 6-13$ months
Classic TN with most common distribution along V2

Painful TN according to the Liverpool criteria

Unilateral TN versus

MS-TN

NA

NA

Mostly V2 and V3 distribution

V1, V2, V3 were affected.

Mostly V2 and V3 distribution

V2 was affected in all patients.

Pontine hemorrhage with injury of the $\mathrm{CN} \mathrm{V}$

Venous malformation in the trigeminal nucleus

L4-5 and L5-S1 LDH

LDH or lumbar SS with/without FS

LDH or FS

Bilateral L5 FS

Unilateral S1 LDH compressing the nerve root

Unilateral L5-S1 LDH compressing the nerve root

Unilateral nerve root compression with L4-5 or L5-S1 LDH

NA
Medically intractable TN pain

NA

NA

Extreme unilateral pain

Unilateral TN

Diagnosis of classic TN

Medically intractable MS-TN pain

NA

Facial pain with tingling and cold sensation

Typical and severe TN

Unilateral radicular pain

NA

Unilateral radicular leg pain

LBP with pain in both legs

Radicular pain

Radicular pain

LBP with leg pain and tingling

Unilateral cluster headache attacks
Radiosurgery resulted in a $47 \%$ drop in the FA values at the target, demonstrating highly focal changes after treatment.

No significant differences were observed in diffusivity of pathways between TN patients and controls.

DTT showed a difference in microstructural changes along the $\mathrm{CN} V$ between the TN group and the MS-TN group.

The descending tract of the trigeminal nerve was visualized in all patients.

The cingulum and the medial forebrain bundle were altered in patients with TN. The posterior cingulum and the MFB-VTA also showed unilateral differences.

Patients with TN showed decreased FA and increased MD and RD on the affected side.

Long-term responders to GKRS showed lower FA and higher RD and MD in the affected nerve.

Preoperative assessment of the trigeminal pathway was a better indicator of GKRS response.

Topographical analysis revealed decreased FA and elevated diffusivity along the entire anatomical S1 arc in patients with TN.

The affected CN V was discontinued at the anterior margin of the pons when compared with the unaffected side.

DTT revealed that the venous malformation was located in the trigeminal nucleus of the middle cerebellar peduncle.

The FA value in compressed spinal nerve roots was lower than that on the unaffected side.

More abnormalities were observed in patients with lumbar SS and especially in patients with FS. The mean FA of the entrapped nerves was low.

Abnormalities were observed in 46 cases (88.5\%) with symptomatic $L 4$ nerve roots and in 21 cases $(91.3 \%)$ with symptomatic S1 nerve roots.

Interruption of fibers was observed at the L5 vertebral foramen on tractography.

The FA value of the compressed nerve roots before surgery was lower than that after surgery, but no difference was observed after the surgery.

The mean FA value of the compressed lumbar nerve roots was significantly lower than that on the unaffected side.

Abnormalities in the symptomatic nerve tracts were observed in the middle or the distal sub-regions in 33 cases $(91.7 \%)$.

Tractography showed highly consistent anatomical connections between altered areas of the brain and the hypothalamus. 
TABLE 1 | Contiued

\begin{tabular}{|c|c|c|c|c|c|c|c|}
\hline S. No. & $\begin{array}{l}\text { First } \\
\text { author }\end{array}$ & Year & $\begin{array}{c}\text { Number of } \\
\text { patients }\end{array}$ & Duration to DTT & Location of lesion & Characteristics of pain & Results \\
\hline 40 & Chong & 2015 & 23 & Mean 18 years & Migraine & Episodic or chronic migraine & $\begin{array}{l}\text { Patients with migraine showed increased MD } \\
\text { and } \mathrm{RD} \text { in the anterior thalamic radiations and } \\
\text { in the CST, with no differences in FA. }\end{array}$ \\
\hline 41 & Coskun & 2017 & 2 & $\begin{array}{l}5 \text { months and } \\
6 \text { years }\end{array}$ & SUNCT & $\begin{array}{l}\text { Severe, excruciating pain in the } \\
\text { periorbital area }\end{array}$ & $\begin{array}{l}\text { Neurovascular compression of the CN V by the } \\
\text { superior cerebellar artery was observed with } \\
\text { decrease in the FA value on the affected side. }\end{array}$ \\
\hline 42 & Jang & 2019 & 2 & $\begin{array}{l}5 \text { months and } \\
10 \text { months }\end{array}$ & $\begin{array}{l}\text { Headache after mild } \\
\qquad \text { TBI }\end{array}$ & $\begin{array}{l}\text { Constant tingling and } \\
\text { intermittent stabbing pain }\end{array}$ & $\begin{array}{l}\text { The STTs showed narrowing in both the } \\
\text { hemispheres and discontinuations at the } \\
\text { subcortical white matter were observed in both } \\
\text { the hemispheres in patient } 2 \text {. }\end{array}$ \\
\hline 43 & Wang & 2020 & 26 & NA & NA & NA & $\begin{array}{l}\text { The FA values of the GON and the cervical DRG } \\
\text { on the symptomatic side were lower than those } \\
\text { on the asymptomatic side. }\end{array}$ \\
\hline \multicolumn{8}{|l|}{ Other } \\
\hline 44 & Manganaro & 2014 & 30 & NA & $\begin{array}{l}\text { Endometriosis and/or } \\
\text { endometriotic nodules }\end{array}$ & $\begin{array}{l}\text { Moderate to severe chronic } \\
\text { pelvic pain }\end{array}$ & $\begin{array}{c}\text { Bilateral abnormalities of S1, S2, and S3 were } \\
\text { observed including disorganized appearance } \\
\text { and decrease in the FA values in the nerve } \\
\text { roots. }\end{array}$ \\
\hline 45 & Magill & 2015 & 1 & $10-15$ years & $\begin{array}{c}\text { Neurogenic thoracic } \\
\text { outlet syndrome }\end{array}$ & Weakness with tingling & $\begin{array}{l}\text { Preoperative tractography revealed the } \\
\text { compression caused by the scalene muscle on } \\
\text { C6 } 6 \text { and C8 nerve roots. }\end{array}$ \\
\hline 46 & Porpora & 2018 & 56 & 36 months & $\begin{array}{l}\text { Endometriosis and/or } \\
\text { adenomyosis }\end{array}$ & Non-cyclic pelvic pain & $\begin{array}{c}\text { Abnormalities in microstructure reconstruction } \\
\text { with fiber disorganization and loss of } \\
\text { unidirectional course were observed in } 44 \\
\text { patients }(66.7 \%) \text {. }\end{array}$ \\
\hline
\end{tabular}

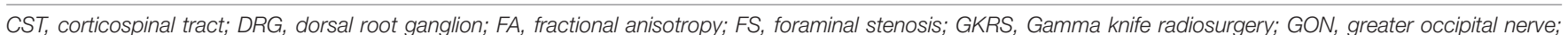

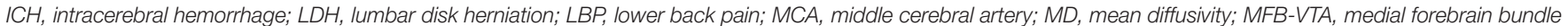

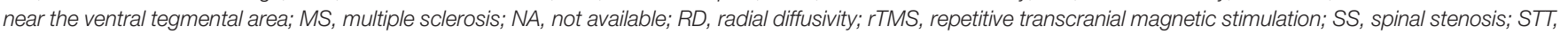

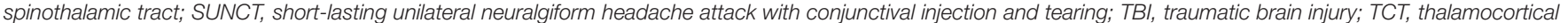

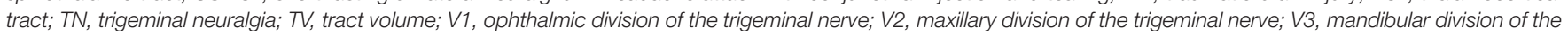
trigeminal nerve.

two groups based on the presence or absence of central pain (22 patients in the pain group and 10 patients in the nonpain group). The STTs were reconstructed by selection of fibers passing through the ROIs. A seed ROI was placed in the STT of the posterolateral medulla. The first target ROI was around the ventral posterolateral nucleus of the thalamus, and the second target ROI was placed at the primary somatosensory cortex (S1). Decreased FA and TV and increased MD of the STTs were observed in patients who had central pain when compared with the control group, suggesting that STT injury was related to the occurrence of central pain. Cases involving patients with mild TBI and central pain were continuously reported in 2016 and 2017 (Jang and Kwon, 2016; Jang and Lee, 2016, 2017). These studies showed that partial tearing of the STTs was associated with the presence of central pain. Choi et al. (2018) used DTT to demonstrate partial STT injury in patients with mild TBI who had chronic central pain. A seed ROI was placed on the posterolateral medulla, and a target ROI was placed at the S1. Six patients who were treated with high-frequency rTMS $(10 \mathrm{~Hz}$ with $90 \%$ intensity of the motor threshold and 1,000 pulses) reported reduction in central pain, suggesting that rTMS can be used to manage chronic central pain. Jang et al. (2019a) used DTT to demonstrate several cases with neural tract damage in patients with central pain. DTT was used to demonstrate STT injury in relation to central pain (Jang et al., 2019a; Jang and Lee, 2019) and to find out STT injury in patients who had atypical type of central pain including abdominal pain (Jang et al., 2020). Interestingly, CST damage was revealed using DTT in patients with CRPS following mild TBI (Jang and Seo, 2020). These studies showed that DTT was useful in detecting STT injuries in patients with central pain after TBI.

\section{Trigeminal Neuralgia}

Trigeminal neuralgia is the most common type of chronic neuropathic facial pain disorder. The trigeminal nerve or the CN V comprises of the ophthalmic, maxillary, and mandibular branches. It controls the sensory and motor functions of the face. TN is characterized by recurrent attacks of sudden-onset, intermittent, highly intense, and shock-like pain over the area of distribution of the trigeminal nerve branches (Elias and Burchiel, 2002). TN is diagnosed clinically by transient or paroxysmal episodes of pain caused by neurovascular compression in the absence of other diseases. In classic TN, patients are often unable to identify the inciting event. In symptomatic $\mathrm{TN}$, patients exhibit identifiable vascular compression of the trigeminal nerve caused by a tumor, multiple sclerosis, or an arteriovenous malformation (Jones et al., 2019). Brain imaging studies including MRI, DTI, and DTT have been performed to investigate the pathophysiology of TN. 


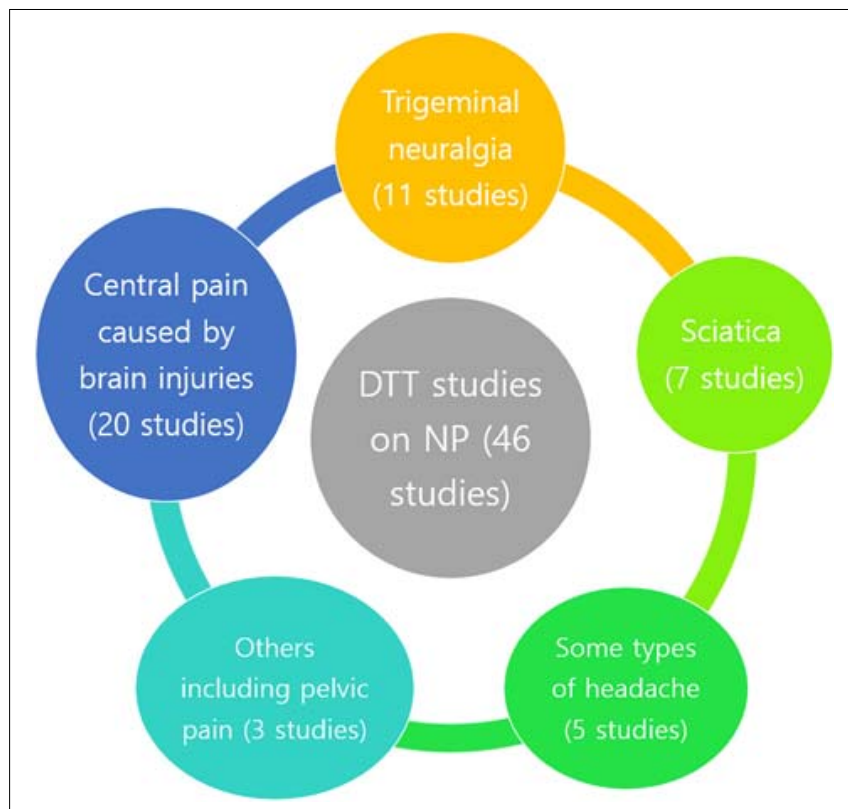

FIGURE 2 | Diffusion tensor tractography studies on NP. DT, diffusion tensor tractography; NP, neuropathic pain.

In 2012, a DTT study on TN was conducted to investigate whether changes can be observed in the target area after radiosurgery for the treatment of TN (Hodaie et al., 2012). This study enrolled five patients with TN, and tractography was used to delineate the course of cranial nerves and to detect changes in the $\mathrm{CN} \mathrm{V}$ after focal radiosurgery for the treatment of TN. In 2015, DTT was used to assess the integrity of ascending pain pathways in 21 patients with painful TN (Wilcox et al., 2015). DTI analysis revealed that orofacial NP was associated with significant increase in FA, decrease in $\mathrm{MD}$, and decrease in the regional gray matter volume within the spinal trigeminal nucleus. Chen et al. (2016) used tractography to examine the differences in $\mathrm{CN} \mathrm{V}$ microstructure between classic TN and TN secondary to multiple sclerosis (MS-TN). Patients with classic TN (10 patients) showed increased FA in the ipsilateral cisternal segment and decreased FA in the ipsilateral root entry/exit zone, whereas patients with MS-TN (10 patients) showed decreased FA in the ipsilateral perilesional segments. This study demonstrated that DTT technique can be used to distinguish different diffusivity changes in $\mathrm{CN} \mathrm{V}$ segments in cases of classic TN and MS-TN. Hayes et al. (2017) used tractography to investigate the impact of $\mathrm{TN}$ on white matter tracts in 37 patients with TN. The results showed that the cingulum and the medial forebrain bundle were altered in patients with TN. Moreover, the posterior cingulum and the medial forebrain bundle near the ventral tegmental area showed unilateral differences between right- and left-sided patients. Moon et al. (2018) used tractography to show that the affected sides of 14 patients with TN showed significantly decreased $\mathrm{FA}$, increased $\mathrm{MD}$, and increased $\mathrm{RD}$ when compared with the unaffected sides.
Additionally, two studies showed that tractography can be used to illustrate microstructural changes in the affected $\mathrm{CN}$ $\mathrm{V}$ before and after GKRS, which is considered an important treatment modality for TN (Tohyama et al., 2018; Li et al., 2019). Changes in FA after GKRS were visualized at the radiosurgical target in long-term responders with classic TN (Tohyama et al., 2018). Decreased myelination at the proximal pontine segment was correlated with poor response to treatment in patients with MS-TN (Li et al., 2019). In 2019, microstructural alterations were observed in the thalamic-somatosensory tracts of patients with TN (Rutland et al., 2019). Moreover, a decrease in FA of the thalamic-somatosensory tract ipsilateral to the site of neurovascular compression was observed, while $\mathrm{MD}$ and $\mathrm{RD}$ were increased ipsilaterally in 10 patients with TN when compared with the control group. Recently, Choi et al. (2020) reported a case showing discontinuation of the $\mathrm{CN} \mathrm{V}$ at the anterior margin of the pons on the side ipsilateral to the one with neuralgic pain after damage from pontine hemorrhage. In another case, DTT elucidated the presence of venous malformation located in the trigeminal nucleus of the middle cerebellar peduncle in intractable TN (Yoshida et al., 2020).

\section{Sciatica}

Sciatica is pain that runs from the lower back down the leg. However, the term has been used widely for a variety of back and leg symptoms (Ropper and Zafonte, 2015). Injury of the lumbosacral nerve roots is most frequently caused by degenerative lumbar disease such as disk herniation, spinal stenosis, and degenerative lumbar spondylosis (Shi et al., 2020). Radicular leg pain is often described as sharp, aching, throbbing, or burning. The causes of radiating leg pain are not fully understood, but the mechanism of sciatica is presumed to be associated with inflammation or damage to the nerve root or the sensory ganglion (Ropper and Zafonte, 2015). Several studies have demonstrated that DTI with tractography is useful in the evaluation and visualization of peripheral nerves including the lumbar nerves.

Chuanting et al. (2014) enrolled 20 patients with L4-L5 and L5-S1 disk herniation who had unilateral radicular leg pain. Tractography was performed using the ROI method. Seed ROIs were placed at the level of the middle spinal body and the spinal disk. The results showed that the mean FA value of the compressed spinal nerve roots was significantly lower than that of the contralateral nerve roots. Oikawa et al. (2015) showed that among 34 patients who had lumbar degenerative disease, patients with lumbar spinal stenosis, especially the ones with foraminal stenosis, showed abnormalities on DTT. In the same year, Shi et al. (2015) suggested that DTT vividly demonstrated abnormalities in the symptomatic nerve tract. Abnormalities were observed in $67(89.3 \%)$ out of 75 patients with radicular leg pain and numbness (Shi et al., 2015). In 2016, a study used DTI with tractography in patients with radicular pain and showed that the FA value of the compressed sacral nerve root was significantly lower than that on the unaffected side. Moreover, the FA value before surgery was significantly lower than that after surgery for compressed sacral nerve root $\mathrm{Wu}$ 
et al., 2016a,b). Another case report described a case of a patient with bilateral L5 lumbar foraminal stenosis who showed an interruption of fibers on tractography at the L5 vertebral foramen (Eguchi et al., 2016). In 2020, a study by Shi et al. (2020) reported that DTT showed distinct abnormalities in the symptomatic nerve tracts in 33 patients $(91.7 \%)$ who had compressed nerve roots.

\section{Headache Including Cluster Headache and Migraine}

Primary headaches cause recurrent or persistent head pain, which can be debilitating, particularly in the chronic form (Mier and Dhadwal, 2018). The diagnosis of primary headaches relies on the history of no apparent underlying cause. Various types of primary headaches include migraine, $\mathrm{CH}$, and SUNCT. The etiology of secondary headaches is unclear. The understanding of the pathophysiology of various types of headaches has continuously evolved and focuses on neuroimaging techniques to study altered sensory processing and brain pathways including neural tract injuries (Mier and Dhadwal, 2018).

Cluster headache presents with periodic and severe unilateral periorbital pain, which can be described as stabbing, squeezing, or burning. Chou et al. (2014) performed tractography on $17 \mathrm{CH}$ patients, which revealed highly consistent anatomical connections between the altered areas (cerebellar tonsil or medial frontal gyrus) and the hypothalamus. This study suggested that descending projections of the hypothalamus may be involved in initiating autonomic responses and $\mathrm{CH}$. Migraine usually presents as unilateral attacks of throbbing head pain with an episodic presentation, which may continue in a chronic or a refractory form. Probabilistic tractography was performed by Chong and Schwedt (2015) in 23 adults with migraine. Migraine patients showed increased $\mathrm{MD}$ and $\mathrm{RD}$ in the left anterior thalamic radiations, the left CST, and the right inferior longitudinal fasciculus tract, with no differences in FA. Interestingly, a positive correlation was observed between years lived with migraine and $\mathrm{MD}$ in the right anterior thalamic radiations and the left CST. SUNCT is one of the trigeminal autonomic cephalagias, which presents as attacks of unilateral head pain and cranial autonomic symptoms. A case report involving two patients with SUNCT showed that tractography was useful in identifying structural changes in the $\mathrm{CN} \mathrm{V}$ secondary to neurovascular compression (Coskun et al., 2017).

Diffusion tensor tractography can be also used to identify the pathophysiology of headache with central pain caused by brain injury. In 2019, a case report showed that STT injury may be associated with posttraumatic headaches following TBI (Jang and Seo, 2019). In 2020, a study on cervicogenic headache, which is classified as a secondary headache arising from degenerative cervical spine disorders, was conducted using tractography in 26 patients (Wang et al., 2020). Tractography of the greater occipital nerves revealed a decrease in FA on the symptomatic side when compared with the asymptomatic side. DTT was useful in elucidating the complex pathophysiology in various types of headaches.

\section{Others}

In addition to the aforementioned disorders and conditions, DTT has been used to assess microstructural changes in other painful conditions such as thoracic outlet syndrome and pelvic pain. Interestingly, Magill et al. (2015) used tractography to visualize compression caused by the scalene muscle on the C6 and C8 nerve root in a patient with neurogenic thoracic outlet syndrome who suffered from right arm weakness and tingling sensation. Endometriosis is a gynecologic disorder associated with pain symptoms including non-cyclic CPP, dysmenorrhea, and dyspareunia. Manganaro et al. (2014) enrolled 30 patients with endometriosis and moderate to severe CPP. DTI with tractography revealed that most of the patients displayed bilateral abnormalities of S1, S2, and S3 including an irregular and disorganized appearance with significant decrease in the FA values in the S1, S2, and S3 roots. Porpora et al. (2018) enrolled 76 patients with endometriosis and evaluated the abnormalities of the sacral root using DTI tractography. Their study also revealed irregularities in the sacral root microstructure associated with non-cyclic CPP.

\section{CONCLUSION}

The diagnosis of NP often relies on the presence of a clinical symptom, and there is no definite diagnostic tool that accurately identifies the exact underlying pathophysiology of NP. Studies in our review showed the possible role of DTT in demonstrating neural injuries in patients with various types of NP. Based on the results of studies included in our review, we suggest that DTT may be an additive diagnostic method for visualizing neural injuries in patients with various types of NP. It is yet insufficient to conclude that DTT is a definite diagnostic tool for NP, but overall, DTT seems to have potential to be useful for defection of underlying pathophysiology of NP. NP may occur when neural tracts are injured; reductions in the fiber density and injuries such as tearing and thinning in neural tracts were observed in NP patients who were suffering from central pain caused by brain injuries, TN, sciatica, and various types of headaches. DTT appears to be useful for isolating neural tract injuries associated with pathologic conditions; it allows visualization of the neural tracts and demonstrates gross fiber architecture. It provides useful quantitative information about muscular tissue and peripheral nerves, and it can also be used to assess microstructural changes at the radiosurgical target to achieve long-lasting pain relief. In the future, DTT may become useful in selecting patients who may benefit from different treatments that target NP and in planning a more personalized therapeutic approach. In addition, DTT assessment can provide prognostic information and guide the clinical decision-making process in patients with NP. Future studies applying this new approach and involving larger patient populations are needed. 


\section{AUTHOR CONTRIBUTIONS}

All authors listed have made a substantial, direct, and intellectual contribution to the work, and approved it for publication.

\section{REFERENCES}

Akyuz, G., and Kuru, P. (2016). Systematic review of central post stroke pain: what is happening in the central nervous system? Am. J. Phys. Med. Rehabil. 95, 618-627. doi: 10.1097/phm.0000000000000542

Assaf, Y., and Pasternak, O. (2008). Diffusion tensor imaging (DTI)-based white matter mapping in brain research: a review. J. Mol. Neurosci. 34, 51-61. doi: 10.1007/s12031-007-0029-0

Baron, R., Binder, A., and Wasner, G. (2010). Neuropathic pain: diagnosis, pathophysiological mechanisms, and treatment. Lancet Neurol. 9, 807-819. doi: 10.1016/s1474-4422(10)70143-5

Boudier-Revéret, M., Hsiao, M. Y., Shyu, S. G., and Chang, M. C. (2020). Injury of corticospinal tract and corticoreticular pathway caused by high-voltage electrical shock: a case report. BMC Neurol. 20:130. doi: 10.1186/s12883-02001707-2

Chen, D. Q., DeSouza, D. D., Hayes, D. J., Davis, K. D., O'Connor, P., and Hodaie, M. (2016). Diffusivity signatures characterize trigeminal neuralgia associated with multiple sclerosis. Mult. Scler. 22, 51-63. doi: 10.1177/ 1352458515579440

Chianca, V., Albano, D., Messina, C., Cinnante, C. M., Triulzi, F. M., Sardanelli, F., et al. (2017). Diffusion tensor imaging in the musculoskeletal and peripheral nerve systems: from experimental to clinical applications. Eur. Radiol. Exp. 1:12. doi: 10.1186/s41747-017-0018-1

Choi, E. B., Seo, J. P., and Jang, S. H. (2020). Diagnosis of the trigeminal nerve injury in a patient with pontine hemorrhage. Diagnostics (Basel) 10:74. doi: 10.3390/diagnostics10020074

Choi, G. S., Kwak, S. G., Lee, H. D., and Chang, M. C. (2018). Effect of highfrequency repetitive transcranial magnetic stimulation on chronic central pain after mild traumatic brain injury: a pilot study. J. Rehabil. Med. 50, 246-252. doi: 10.2340/16501977-2321

Chong, C. D., and Schwedt, T. J. (2015). Migraine affects white-matter tract integrity: a diffusion-tensor imaging study. Cephalalgia 35, 1162-1171. doi: 10.1177/0333102415573513

Chou, K. H., Yang, F. C., Fuh, J. L., Huang, C. C., Lirng, J. F., Lin, Y. Y., et al. (2014). Altered white matter microstructural connectivity in cluster headaches: a longitudinal diffusion tensor imaging study. Cephalalgia 34, 1040-1052. doi: 10.1177/0333102414527649

Chuanting, L., Qingzheng, W., Wenfeng, X., Yiyi, H., and Bin, Z. (2014). 3.0T MRI tractography of lumbar nerve roots in disc herniation. Acta Radiol. 55, 969-975. doi: $10.1177 / 0284185113508179$

Cohen, S. P., and Mao, J. (2014). Neuropathic pain: mechanisms and their clinical implications. BMJ 348:f7656. doi: 10.1136/bmj.f7656

Coskun, O., Ucar, M., Vuralli, D., Yildirim, F., Cetinkaya, R., Akin Takmaz, S., et al. (2017). MR tractography in short lasting unilateral neuralgiform headache attacks with conjunctival injection and tearing (SUNCT) patients: case reports. Pain Med. 18, 1377-1381. doi: 10.1093/pm/pnw334

Eguchi, Y., Ohtori, S., Suzuki, M., Oikawa, Y., Yamanaka, H., Tamai, H., et al. (2016). Diagnosis of lumbar foraminal stenosis using diffusion tensor imaging. Asian Spine J. 10, 164-169. doi: 10.4184/asj.2016.10.1.164

Elias, W. J., and Burchiel, K. J. (2002). Trigeminal neuralgia and other neuropathic pain syndromes of the head and face. Curr. Pain Headache Rep. 6, 115-124. doi: 10.1007/s11916-002-0007-8

Goto, T., Saitoh, Y., Hashimoto, N., Hirata, M., Kishima, H., Oshino, S., et al. (2008). Diffusion tensor fiber tracking in patients with central post-stroke pain; correlation with efficacy of repetitive transcranial magnetic stimulation. Pain 140, 509-518. doi: 10.1016/j.pain.2008.10.009

Hayes, D. J., Chen, D. Q., Zhong, J., Lin, A., Behan, B., Walker, M., et al. (2017). Affective circuitry alterations in patients with trigeminal neuralgia. Front. Neuroanat. 11:73. doi: 10.3389/fnana.2017.00073

\section{FUNDING}

The present study was supported by a National Research Foundation of Korea grant funded by the Korean Government (grant no. NRF-2019M3E5D1A02068106).

Hirayama, T., Ikeda, K., Kawabe, K., Ishikawa, Y., Iwamoto, K., Harada, H., et al. (2014). A case of superficial hemisensory dysfunction due to operculoinsular infarction: radiological depiction of thalamocortical projections to the secondary somatosensory cortex. J Stroke Cerebrovasc. Dis. 23, 187-190. doi: 10.1016/j.jstrokecerebrovasdis.2012.11.010

Hodaie, M., Chen, D. Q., Quan, J., and Laperriere, N. (2012). Tractography delineates microstructural changes in the trigeminal nerve after focal radiosurgery for trigeminal neuralgia. PLoS One 7:e32745. doi: 10.1371/journal. pone. 0032745

Hong, J. H., Bai, D. S., Jeong, J. Y., Choi, B. Y., Chang, C. H., Kim, S. H., et al. (2010). Injury of the spino-thalamo-cortical pathway is necessary for central post-stroke pain. Eur. Neurol. 64, 163-168. doi: 10.1159/000319040

Jang, S. H., Chang, C. H., Jung, Y. J., and Lee, H. D. (2017a). Delayed-onset central pain due to degeneration of ischemic transcallosal fibers after corpus callosum hemorrhage. Am. J. Phys. Med. Rehabil. 96, e177-e180. doi: 10.1097/ phm.0000000000000693

Jang, S. H., Kim, J., and Lee, H. D. (2018). Delayed-onset central poststroke pain due to degeneration of the spinothalamic tract following thalamic hemorrhage: a case report. Medicine (Baltimore) 97, e13533. doi: 10.1097/md. 0000000000013533

Jang, S. H., and Kwon, H. G. (2016). Degeneration of an injured spinothalamic tract in a patient with mild traumatic brain injury. Brain Inj. 30, 1026-1028. doi: 10.3109/02699052.2016.1146961

Jang, S. H., Kwon, Y. H., and Lee, S. J. (2019a). Central pain due to injury of the spinothalamic tract misdiagnosed as complex regional pain syndrome: a case report. Diagnostics (Basel) 9:145. doi: 10.3390/diagnostics9040145

Jang, S. H., Kwon, Y. H., and Lee, S. J. (2020). Abdominal pain due to the spinothalamic tract injury in patients with mild traumatic brain injury: a case report. BMC Neurol. 20:117. doi: 10.1186/s12883-020-01695-3

Jang, S. H., and Lee, H. D. (2016). Central pain due to spinothalamic tract injury caused by indirect head trauma following a pratfall. Brain Inj. 30, 933-936. doi: $10.3109 / 02699052.2016 .1146966$

Jang, S. H., and Lee, H. D. (2017). Traumatic axonal injury despite clinical phenotype of mild traumatic brain injury: a case report. Brain Inj. 31, 15341537. doi: 10.1080/02699052.2017.1376754

Jang, S. H., and Lee, H. D. (2019). Diagnostic approach to traumatic axonal injury of the spinothalamic tract in individual patients with mild traumatic brain injury. Diagnostics (Basel) 9:199. doi: 10.3390/diagnostics9040199

Jang, S. H., Lee, J., and Yeo, S. S. (2017b). Central post-stroke pain due to injury of the spinothalamic tract in patients with cerebral infarction: a diffusion tensor tractography imaging study. Neural Regen. Res. 12, 2021-2024. doi: 10.4103/ 1673-5374.221159

Jang, S. H., Seo, J. P., and Lee, S. J. (2019b). Diffusion tensor tractography studies of central post-stroke pain due to the spinothalamic tract injury: a mini-review. Front. Neurol. 10:787. doi: 10.3389/fneur.2019.00787

Jang, S. H., and Seo, Y. S. (2019). Headache due to spinothalamic tract injury in patients with mild traumatic brain injury: two case reports. Medicine (Baltimore) 98:e14306. doi: 10.1097/md.0000000000014306

Jang, S. H., and Seo, Y. S. (2020). Diagnosis of complex regional pain syndrome $i$ following traumatic axonal injury of the corticospinal tract in a patient with mild traumatic brain injury. Diagnostics (Basel) 10:95. doi: 10.3390/ diagnostics 10020095

Jones, M. R., Urits, I., Ehrhardt, K. P., Cefalu, J. N., Kendrick, J. B., Park, D. J., et al. (2019). A comprehensive review of trigeminal neuralgia. Curr. Pain Headache Rep. 23:74. doi: 10.1007/s11916-019-0810-0

Kim, J. H., Ahn, S. H., Cho, Y. W., Kim, S. H., and Jang, S. H. (2015). The relation between injury of the spinothalamocortical tract and central pain in chronic patients with mild traumatic brain injury. J. Head Trauma Rehabil. 30, E40-E46. doi: $10.1097 /$ htr.0000000000000121 
Klit, H., Finnerup, N. B., and Jensen, T. S. (2009). Central post-stroke pain: clinical characteristics, pathophysiology, and management. Lancet Neurol. 8, 857-868. doi: 10.1016/s1474-4422(09)70176-0

Lee, A., Jung, Y., Kwon, H. K., and Pyun, S. B. (2018). Complex regional pain syndrome of non-hemiplegic upper limb in a stroke patient: a case report. Ann. Rehabil. Med. 42, 175-179. doi: 10.5535/arm.2018.42.1.175

Li, C. M. F., Hung, P. S., Chu, P. P., Tohyama, S., and Hodaie, M. (2019). Trigeminal neuralgia associated with multiple sclerosis: a multimodal assessment of brainstem plaques and response to Gamma Knife radiosurgery. Mult. Scler. 26, 1877-1888. doi: 10.1177/1352458519886070

Magill, S. T., Brus-Ramer, M., Weinstein, P. R., Chin, C. T., and Jacques, L. (2015) Neurogenic thoracic outlet syndrome: current diagnostic criteria and advances in MRI diagnostics. Neurosurg. Focus 39:E7. doi: 10.3171/2015.6.Focus15219

Manganaro, L., Porpora, M. G., Vinci, V., Bernardo, S., Lodise, P., Sollazzo, P., et al. (2014). Diffusion tensor imaging and tractography to evaluate sacral nerve root abnormalities in endometriosis-related pain: a pilot study. Eur. Radiol. 24, 95-101. doi: 10.1007/s00330-013-2981-0

Mier, R. W., and Dhadwal, S. (2018). Primary headaches. Dent. Clin. North Am. 62, 611-628. doi: 10.1016/j.cden.2018.06.006

Moon, H. C., You, S. T., Baek, H. M., Jeon, Y. J., Park, C. A., Cheong, J. J., et al. (2018). 7.0 Tesla MRI tractography in patients with trigeminal neuralgia. Magn. Reson. Imaging 54, 265-270. doi: 10.1016/j.mri.2017.12.033

Oh, J., Jung, J. Y., and Ko, Y. J. (2018). Can diffusion tensor imaging and tractography represent cross-sectional area of lumbar multifidus in patients with LUMBAR spine disease? Muscle Nerve 57, 200-205. doi: 10.1002/mus. 25639

Oikawa, Y., Eguchi, Y., Inoue, G., Yamauchi, K., Orita, S., Kamoda, H., et al. (2015). Diffusion tensor imaging of lumbar spinal nerve in subjects with degenerative lumbar disorders. Magn. Reson. Imaging 33, 956-961. doi: 10.1016/j.mri.2015. 05.002

Porpora, M. G., Vinci, V., De Vito, C., Migliara, G., Anastasi, E., Ticino, A., et al. (2018). The role of magnetic resonance imaging-diffusion tensor imaging in predicting pain related to endometriosis: a preliminary study. J. Minim. Invasive Gynecol. 25, 661-669. doi: 10.1016/j.jmig.2017.10.033

Ropper, A. H., and Zafonte, R. D. (2015). Sciatica. N. Engl. J. Med. 372, 1240-1248. doi: 10.1056/NEJMra1410151

Rutland, J. W., Huang, K. H., Gill, C. M., Villavisanis, D. F., Alper, J., Verma, G., et al. (2019). First application of 7-T ultra-high field diffusion tensor imaging to detect altered microstructure of thalamic-somatosensory anatomy in trigeminal neuralgia. J. Neurosurg. doi: 10.3171/2019.6.Jns19541 [Epub ahead of print].

Seghier, M. L., Lazeyras, F., Vuilleumier, P., Schnider, A., and Carota, A. (2005). Functional magnetic resonance imaging and diffusion tensor imaging in a case of central poststroke pain. J. Pain 6, 208-212. doi: 10.1016/j.jpain.2004.11.004

Seo, J. P., and Jang, S. H. (2013). Traumatic thalamic injury demonstrated by diffusion tensor tractography of the spinothalamic pathway. Brain Inj. 27, 749-753. doi: 10.3109/02699052.2013.771794

Seo, J. P., and Jang, S. H. (2014). Injury of the spinothalamic tract in a patient with mild traumatic brain injury: diffusion tensor tractography study. J. Rehabil. Med. 46, 374-377. doi: 10.2340/16501977-1783
Shi, Y., Zong, M., Xu, X., Zou, Y., Feng, Y., Liu, W., et al. (2015). Diffusion tensor imaging with quantitative evaluation and fiber tractography of lumbar nerve roots in sciatica. Eur. J. Radiol. 84, 690-695. doi: 10.1016/j.ejrad.2015.01.006

Shi, Y., Zou, Y., Feng, Y., Dou, W., Ding, H., Wang, C., et al. (2020). A quantitative and clinical evaluation of nerve roots in lumbosacral radiculopathy using diffusion tensor imaging. Jpn. J. Radiol. 38, 222-230. doi: 10.1007/s11604-01900913-4

Tohyama, S., Hung, P. S., Zhong, J., and Hodaie, M. (2018). Early postsurgical diffusivity metrics for prognostication of long-term pain relief after Gamma Knife radiosurgery for trigeminal neuralgia. J. Neurosurg. 131, 539-548. doi: 10.3171/2018.3.Jns172936

Wang, L., Shen, J., Das, S., and Yang, H. (2020). Diffusion tensor imaging of the C1-C3 dorsal root ganglia and greater occipital nerve for cervicogenic headache. Korean J. Pain 33, 275-283. doi: 10.3344/kjp.2020.33. 3.275

Wilcox, S. L., Gustin, S. M., Macey, P. M., Peck, C. C., Murray, G. M., and Henderson, L. A. (2015). Anatomical changes at the level of the primary synapse in neuropathic pain: evidence from the spinal trigeminal nucleus. J. Neurosci. 35, 2508-2515. doi: 10.1523/jneurosci.3756-14.2015

Wu, W., Liang, J., Chen, Y., Chen, A., Wu, B., and Yang, Z. (2016a). Microstructural changes in compressed nerve roots treated by percutaneous transforaminal endoscopic discectomy in patients with lumbar disc herniation. Medicine (Baltimore) 95:e5106. doi: 10.1097/md.0000000000005106

Wu, W., Liang, J., Ru, N., Zhou, C., Chen, J., Wu, Y., et al. (2016b). Microstructural changes in compressed nerve roots are consistent with clinical symptoms and symptom duration in patients with lumbar disc herniation. Spine (Phila $\mathrm{Pa}$ 1976) 41, E661-E666. doi: 10.1097/brs.0000000000001354

Yang, S., and Chang, M. C. (2020). Effect of repetitive transcranial magnetic stimulation on pain management: a systematic narrative review. Front. Neurol. 11:114. doi: 10.3389/fneur.2020.00114

Yoshida, S., Shin, M., Kin, T., and Saito, N. (2020). 3-dimensional computer graphics model elucidating involvement of intraparenchymal venous malformation in trigeminal nucleus of brachium pontis with intractable trigeminal neuralgia. J. Clin. Neurosci. 76, 205-207. doi: 10.1016/j.jocn.2020.04.042

Zhang, Y., Vakhtin, A. A., Jennings, J. S., Massaband, P., Wintermark, M., Craig, P. L., et al. (2020). Diffusion tensor tractography of brainstem fibers and its application in pain. PLoS One 15:e0213952. doi: 10.1371/journal.pone.0213952

Conflict of Interest: The authors declare that the research was conducted in the absence of any commercial or financial relationships that could be construed as a potential conflict of interest.

Copyright (c) 2021 Yang, Kwon and Chang. This is an open-access article distributed under the terms of the Creative Commons Attribution License (CC BY). The use, distribution or reproduction in other forums is permitted, provided the original author(s) and the copyright owner(s) are credited and that the original publication in this journal is cited, in accordance with accepted academic practice. No use, distribution or reproduction is permitted which does not comply with these terms. 